\title{
Let-7d Inhibits Growth and Metastasis in Breast Cancer by Targeting Jab1/Cops5
}

\author{
Yongchang Wei ${ }^{a}$ Guohong Liu ${ }^{b}$ Balu Wu ${ }^{c}$ Yufen Yuan ${ }^{d}$ Yunbao Pane,f \\ aDepartment of Clinical Oncology, Zhongnan Hospital of Wuhan University, Wuhan University, Wuhan, \\ ${ }^{b}$ Department of Radiology, Zhongnan Hospital of Wuhan University, Wuhan University, Wuhan, \\ 'Department of Hematology, Zhongnan Hospital of Wuhan University, Wuhan University, Wuhan, \\ dDepartment of Pathology, Anyang Tumor Hospital, Anyang, Henan, eDepartment of Laboratory \\ Medicine, Zhongnan Hospital of Wuhan University, Wuhan University, Wuhan, Hubei, 'BBreast Tumor \\ Center, Sun Yat-Sen Memorial Hospital, Sun Yat-Sen University, Guangzhou, Guangdong, China
}

\section{Key Words}

Breast cancer $\bullet$ Let-7d $\bullet$ Jab1 $\bullet$ COPS5 $\bullet$ CSN5 $・$ Biomarker

\begin{abstract}
Background/Aims: MicroRNAs (miRNAs) regulate the expressions of cancer-related genes, and are involved in the development and progression of various human cancers. Here, we performed further analyses to determine whether let-7d is functionally linked to Jab1 in breast cancer. Methods: In situ hybridization and immunohistochemical analyses were used to determine the level of let-7d and Jab1 in breast cancer clinical specimens and its correlation with clinicopathological data. Let-7d overexpressing breast cancer cell lines combined with mouse models bearing cell-derived xenografts were used to assess the functional role of let$7 d$ both in vitro and in vivo. Results: In this study, we found that let-7d was downregulated in breast cancer tissues, coupled with the elevations of Jab1 protein expressions, compared with paired adjacent noncancerous breast tissues. Let-7d overexpression significantly suppressed the proliferation and invasion in MCF-7 and MDA-MB-231 cells. Dual luciferase reporter assay indicated that Jab1 was the direct target of let-7d. Stepwise studies from in vitro and in vivo experiments indicated that let-7d overexpression inhibited cell growth and decreased Jab1 expressions in breast cancer cells and nude mice tumor tissues. Statistical analyses demonstrated that breast cancer patients with low levels of let-7d or high levels of Jab1 had a significant correlation with worse prognosis. Conclusion: These findings provide novel insights into molecular mechanism of let-7d and Jab1 in tumor development and progression of breast cancer, and thus let-7d/Jab1 are novel potential therapeutic targets for breast cancer patients.
\end{abstract}

\section{Introduction}

Breast cancer is the most common malignancy and the second leading cause of cancer deaths among women worldwide [1]. Etiologic studies have demonstrated that environmental factors, genetic susceptibility, and reproductive factors are associated with 
breast cancer [2,3]. Despite recent progress in adjuvant therapies, the 5-year survival rate of stage IV advanced breast cancer is only $22 \%$ [1]. More than $90 \%$ death of the breast cancer patients have been attributed to metastasis [4]. These features conferred different prognosis and response to therapies in breast cancer [5]. Therefore, there is dire need of identifying novel molecular targets for breast cancer.

Jab1, also known as COPS5 or CSN5, regulates cell proliferation by functionally regulating several key tumor-related genes [6-9]. It has also been reported that overexpression of Jab1 enhances pro-survival pathways in breast cancer [7, 10]. In breast carcinogenesis, Jab1 is associated with EGFR and HER-2 receptors and their downstream signaling factors that contribute to the cancer progress [8]. However, whether the increased expression of Jab1 is regulated by non-coding RNAs has not been elucidated in breast cancer.

MicroRNAs (miRNAs) are a group of endogenous small non-coding RNAs that negatively regulate gene expression via binding with the 3'UTR of the target mRNA [11, 12]. MiRNAs are involved in various biological processes such as cell proliferation, differentiation, and apoptosis [13], and may be novel molecular targets for tumor patients $[14,15]$. The let-7 family consists of 13 family members. Let- 7 is undetectable in human and mouse embryonic stem cells, but appears in embryogenesis and differentiation [16]. Elevated let-7 is subsequently maintained in various adult tissue [17]. In contrast, decreased expression of let-7 has been detected in human cancers, including hepatocellular carcinoma, breast cancer, and lung cancer [18-20], possibly indicating the reverse embryogenesis process occurs during tumorigenesis [21].

Let-7 family, including let-7d, was reported to inhibit tumor pathogenesis [20, 22]. On the other hand, let-7d contributes to the pathogenesis of some cancers. For instance, it was reported that let-7d exerted both anti-oncogenic and oncogenic effects in osteosarcoma [23]. Besides this, let-7d directly targeted CCL7, COL3A1, HMGA2 [23], and PBX3 [24, 25], and inhibited cell growth, invasion, and metastasis.

In the present study, we found that let-7d inhibits breast cancer by directly targeting Jab1, indicating a tumor suppressor role for let-7d in breast cancer. Our findings indicates that the restoration of let-7 $\mathrm{d}$ in cancers provides a promising therapeutic strategy for breast cancer.

\section{Materials and Methods}

\section{Tissue Micro Array}

Samples were collected from 140 invasive breast cancer patients who received initial surgery and didn't receive preoperative chemoradiotherapy at Anyang Tumor Hospital between 2005 and 2006, and were used for constructing Tissue Micro Array (TMA). Separate TMAs were also created from archived, formalin-fixed paraffin-embedded tissues from 30 breast cancer tissue and 30 matched adjacent noncancerous breast tissue specimens. This study was carried out in accordance with the recommendations of Anyang Tumor Hospital Ethics and Scientific Committee, and written informed consent was received from each patient. All the patients gave written informed consent in accordance with the Declaration of Helsinki. Finally. protocols were approved by the Anyang Tumor Hospital Ethics and Scientific Committee. The clinical and pathological characteristics of 30 breast cancer and 140 breast cancer patients have been summarized (for all online suppl. material, see www.karger.com/doi/10.1159/000491523) in Suppl. Table 1 and Table 1.

\section{Cell lines}

The human breast cancer cell lines MDA-MB-231 and MCF-7 were obtained from the American Type Culture Collection, and then cultured in RPMI-1640 supplemented with 10\% fetal bovine serum (FBS), 100 $\mathrm{U}$ of penicillin $/ \mathrm{ml}$, and $100 \mu \mathrm{g}$ of streptomycin $/ \mathrm{ml}$. All the cells were incubated at $37^{\circ} \mathrm{C}$ in a humidified chamber supplemented with $5 \% \mathrm{CO}_{2}$.

Chemicals and reagents

All the cell culture media were purchased from Gibco (Grand Island, NY, USA). Let-7d mimics and the inhibitor was purchased from GenePharma (Shanghai, China). Lentiviral miRNA expression system was 


\section{Cellular Physiology Cell Physiol Biochem 2018;47:2126-2135

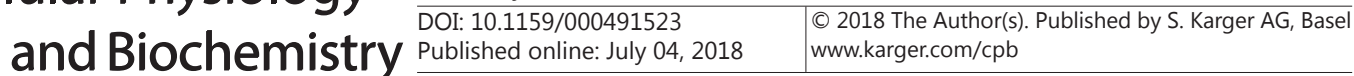 \\ Wei et al.: Let-7d Targets Jab1 in Breast Cancer}

purchased from GenePharma (Shanghai, China). The anti-Jab1 antibody was purchased from Santa Cruz Biotechnology (Santa Cruz, CA, USA), and anti- $\beta$-actin was purchased from Sigma-Aldrich (St. Louis, MO, USA). Dual-luciferase Reporter Assay System was purchased from Promega (Madison, WI, USA).

\section{Immunohistochemical and in situ hybridization analyses}

All the immunohistochemical (IHC) and in situ hybridization (ISH) analyses were performed on the TMA. For IHC staining on TMA, $4 \mu \mathrm{m}$ thick paraffin-embedded tissue sections were mounted on slides. The IHC procedure was conducted as described in our previous work [26].

For ISH staining on TMA, Digoxigenin (DIG) labeled probes for let-7d were purchased from Exiqon. The tissue slides were hybridized with the double-DIG labeled microRNA probe for 2 hours. The DIG was then examined by anti-DIG antibody. Cancer cells were regarded as positive for let-7d when cytoplasmic or nuclear staining was present. The positivity represented the estimated fraction of positively stained cells.

\section{Let-7d mimic and inhibitor transfection}

Cells were seeded into six-well plates overnight, and then miRNA mimic, miRNA inhibitor, or miRNA control were transfected using Lipofectamine 2000 according to the supplier's protocol. The total protein and RNA were extracted after 48 hours' transfection.

\section{Cell viability assay}

We used the MTT assay to assess cell viability as previously reported [27]. Briefly, cells were plated in 96-well plates (500 cells/well for growth) in $100 \mu \mathrm{L}$ of RPMI-1640 medium. After the indicated incubation time, MTT reagent $(0.5 \mathrm{mg} / \mathrm{mL})$ was added, and the absorbance was measured using a microplate reader at $570 \mathrm{~nm}$.

\section{Cell Invasion Assay}

A cell invasion assay was performed using a BD BioCoat Matrigel invasion chamber (Franklin Lakes, NJ) as previously described [26]. Breast cancer cells were incubated in the upper chamber at a density of 2000 cells/well. Cell invasion into Matrigel was determined after 12 hours. The cells invading the membrane were stained with crystal violet and quantified using an inverted-contrast microscope.

\section{Lentivirus infection and let-7d stable expression}

MDA-MB-231 cells were seeded into a 12-well plate and infected with $100 \mu \mathrm{L}$ of lentivirus carrying has-let-7 d or mir-LV-control was added. When cell confluence was greater than $50 \%$, then the infected cells were selected by puromycin $(4 \mu \mathrm{g} / \mathrm{mL})$. Colonies were harvested to determine the efficiency of stable cells overexpressing let-7d.

\section{Cell extracts and immunoblotting}

Cells were harvested and lysed as previously reported [27]. Western blotting was performed using antibodies against Jab1 antibody and $\beta$-actin was used as the internal control. Immunoreactive bands were examined using horseradish peroxidase-conjugated secondary antibodies.

\section{Dual Luciferase Reporter Assay}

Luciferase plasmids (pMIR) containing 3'-UTR of Jab1 was transiently transfected with let-7d mimics into breast cancer cells as previously described [28]. After 48 hours, cells were washed and resuspended in the lysis buffer, and the luciferase activity was measured with a luminometer using the Dual-Light system.

RNA extraction and quantitative real-time polymerase chain reaction (PCR)

Total RNA was extracted using Trozol regent (Ambion), and detected by quantitative PCR using commercially available TaqMan gene expression assays from Applied Biosystems for the let-7d and Jab1. U6 snRNA and GAPDH were used to normalize let-7d and Jab1 expression, respectively.

Tumorigenicity assay in nude mice

Four-week-old athymic nude (nu/nu) mice were bred and maintained under defined conditions at the Animal Experiment Center of Wuhan University, and all the procedures was approved by the Animal 


\section{Cellular Physiology Cell Physiol Biochem 2018;47:2126-2135 \begin{tabular}{ll|l} 
and Biochemistry Published online: July 04, 2018 & $\begin{array}{l}\text { (c) } 2018 \text { The Author(s). Published by S. Karger AG, Basel } \\
\text { www.karger.com/cpb }\end{array}$
\end{tabular} \\ Wei et al.: Let-7d Targets Jab1 in Breast Cancer}

Care and Use Committee of Wuhan University. MCF-7 cells $\left(5.0 \times 10^{6}\right)$ stably overexpressing has-let-7d or miR-control vector were subcutaneously injected into the right back of the mice $(\mathrm{n}=5$ /group). Mice were checked every $3 \mathrm{~d}$ for xenograft development. Tumors were monitored twice every week. Tumor volume was calculated using the formula: volume $=\left(\mathrm{L} \times \mathrm{W}^{2}\right) / 2$. Mice were killed on day 42, and tumors were weighed after careful resection.

Analysis of correlations between let-7d and Jab1 and patients survival

Two online databases, Kaplan-Meier Plotter [29] (http://kmplot.com/analysis/) and PROGgeneV2PROGNOSTICS [30] (http://watson.compbio. iupui.edu/chiray u/proggene/database/) were used to examine whether let-7d and Jab1 were associated with the breast cancer patients' overall survival (OS) and metastasis-free survival (MFS).

\section{Statistical analyses}

Overall survival (OS) and metastasis-free survival (MFS) were defined as the time from the date of diagnosis to the date of death or metastasis respectively. Kaplan-Meier analysis was executed to assess the association between let-7d or Jab1 expression and survival. The results were analyzed by using Student's $t$ test when only 2 groups were examined or by using one-way analysis of variance when more than 2 groups were examined. Differences were considered to be statistically significant when $\mathrm{P}$ $<0.05$. All the computations were performed by SPSS 22.0 software (SPSS).

\section{Results}

\section{Patient characteristics}

Samples from 140 patients with breast cancer (median age, 54 years; range, 29-87 years) and 30 patients with paired adjacent noncancerous breast tissue specimens and breast cancer tissue (median age, 49 years; range, 29-74 years) were used in this study. The breast cancer patients' clinical characteristics are shown in Table 1.

Let-7d and Jab1 expression in breast cancer

To measure the expression levels of both let-7d and Jab1 in breast cancer tissues and noncancerous breast tissues, we did in situ hybridization and immunohistochemical analyses. In situ hybridization analysis revealed that the nuclear and cytoplasmic expression of let- $7 \mathrm{~d}$ in breast cancer samples was $15 \%$ and $34 \%$, respectively. This proportion was lower than that in the paired adjacent noncancerous breast tissue specimens, which was $42 \%$ in the nucleus and $52 \%$ in the cytoplasm $(\mathrm{P}<0.01$; Fig. 1A). In contrast, immunohistochemical analysis revealed that expression level of Jab1 in

Table 1. Characteristics of breast cancer patients $(\mathrm{n}=$ 140)

\begin{tabular}{lc}
\hline Variable & Number (\%) \\
\hline Age & \\
$<60$ & $93(66.4 \%)$ \\
$\geq 60$ & $47(33.6 \%)$ \\
Histological type & \\
Ductal & $130(92.9 \%)$ \\
Lobular \& mucinous & $10(7.1 \%)$ \\
Stage & \\
I & $33(23.6 \%)$ \\
II & $61(43.6 \%)$ \\
III \& IV & $46(32.9 \%)$ \\
Grade & \\
G2 & $98(70.0 \%)$ \\
G3 & $42(30.0 \%)$ \\
Tumor size & \\
T1 & $57(40.7 \%)$ \\
T2 & $81(57.9 \%)$ \\
T3 \& T4 & $2(1.4 \%)$ \\
Lymph node metastasis & \\
No & \\
Yes & $76(54.3 \%)$ \\
Distant metastasis & $64(45.7 \%)$ \\
No & \\
Yes & $129(92.1 \%)$ \\
HER2 & \\
negative & \\
positive & \\
ER & \\
negative & \\
positive & \\
negative & \\
\hline
\end{tabular}


breast cancer tissues was $(84 \%$ in the nucleus and $80 \%$ in the cytoplasm) were higher than those observed in the paired adjacent noncancerous tissue (47\% and 52\%; $\mathrm{P}<0.01$; Fig. 1B).

Let-7d inhibits cell proliferation and invasion in breast cancer

As our previous study showed that loss of Jab1 suppresses tumor cell proliferation [31]. Therefore, we were interested in determining whether let-7d-mediated Jab1 inhibition could recapitulate this tumor-suppressor effect on breast cancer. Results show that let-7d significantly inhibited cell growth in breast cancer cells (Fig. 2A and 2B). We also assessed the effect of let-7d on cell invasion. Using an in vitro invasion assay, we found that let-7d significantly decreased breast cancer cell invasion (Fig. 2C).

Since in vitro findings indicated that let-7d has a critical role in breast cancer. To explore the potential role of let-7d in vivo, we established breast cancer cells stably overexpression of let-7d by infecting MCF-7 cells with a lentivirus carrying let$7 \mathrm{~d}$. Then we selected colonies to verify let-7d expression by qRTPCR analysis. Results of qRTPCR analysis demonstrated that approximately 12 -fold and 8 -fold let-7d levels were increased in colony \#1 and colony \#2, respectively, compared with the cells expressing mir-LV- control (Fig. 3A).

We then transplanted the colony \#1 cells into nude mice. The suppressive effects of let-7d on tumor growth were evident in the MCF-7 mouse model

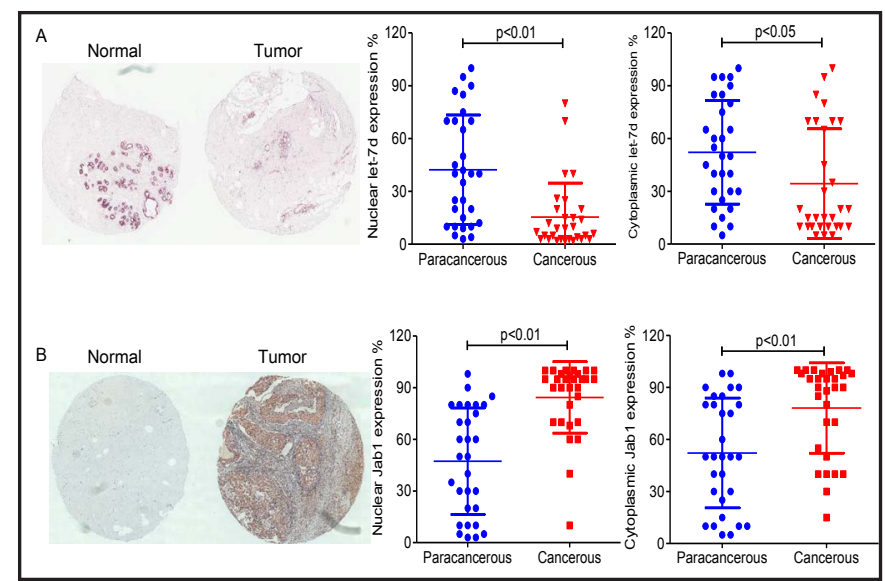

Fig. 1. Expression patterns of let-7d and Jab1 in breast cancer tissue and matched adjacent noncancerous tissue. (A) Overall, let-7d immunoreactivity in noncancerous tissues was higher than that in breast cancer tissues. The percentages of let-7d expression in noncancerous breast tissues or breast cancer tissues are shown. (B) Overall, Jab1 immunoreactivity in noncancerous tissues was lower than that in breast cancer tissues. The percentages of Jab1 expression in noncancerous breast tissues or breast cancer tissues are shown. P values were from Student's t test.

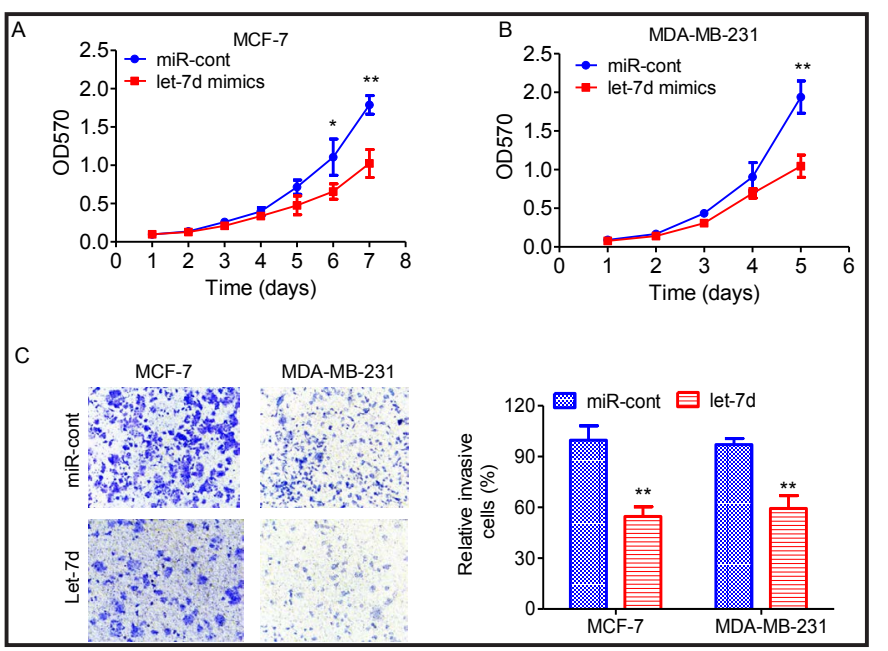

Fig. 2. Let-7d inhibits cell proliferation and invasion in breast cancer. (A, B) breast cancer cells MCF-7 (A) and MDA-MB-231 (B) were transfected with let-7d mimics for 48 hours, and cell growth was determined via MTT assay. (C) The cell invasion assay was performed using the invasion chamber assay. Matrigel membranes containing invading cells were observed via optical microscopy, and the cells were counted. The number of invading cells from each cell population was quantified. The data are means with standard deviations for three independent experiments. ${ }^{*} \mathrm{P}<0.05,{ }^{*} \mathrm{P}<0.01$.

(Fig. 3B). The let-7d xenograft grew much more slowly than mir-LV- control xenograft did. Tumor weight was consistently significantly lower in the let-7d groups than in the mir-LV- 
control group (Fig. 3C). We further assessed Jab1 expression in tumor xenograft tissues. Immunostaining showed that Jab1 was abundantly expressed in the mir-LV-control tumor, whereas expression of Jab1 was reduced in the let-7d overexpressing tumor (Fig. 3D). These data confirmed that let-7d associated with Jab1 in breast cancer.

\section{Let-7d negatively regulates Jab1 in breast cancer}

The above data demonstrated that Jab1 has the opposite expression level of let-7d in breast cancer patients. We thus hypothesized that Jab1 might be a target of let-7d. We used RNAhybrid to identify the binding motifs of let-7d to the 3'UTR of Jab1 as previously described [28]. It was found that 3'UTR of Jab1 harbored a targeting sequence by let-7d with applicable MFE (Minimum Free Energies, MFE: $-15.9 \mathrm{kcal} / \mathrm{mol}$ ) (Fig. 4A). In addition, the expression of

Fig. 3. Let-7d suppresses tumor growth in vivo. (A) MCF-7 cells were transduced with a lentivirus overexpressing let-7d. qRT-PCR analysis of let-7d expression level in two colonies \#1 and \#2 are presented as the mean \pm s.d. U6 snRNA was served as an internal control. (B) Let-7d induced tumor regression and slowed the rate of tumor growth compared with miR-Control. BALB/c athymic nu/nu mice with tumors and resected tumors are shown $(n=5$ per group). (C) Weight of xenograft tumors was significantly decreased by let-7d overexpressing compared with control. (D) Representative Jab1 expression in tissue from the same mice as in panels $\mathrm{B} .{ }^{* *} \mathrm{P}<0.001$.

Fig. 4. Let-7d directly targets Jab1 mRNA. (A) In silico prediction of the binding sites of let-7d to Jab1 at 3'UTR by RNAhybrid was shown. Mfe: minimum free energy. 3'UTR: 3' untranslated region. (B) Let-7d expression was correlated with Jab1 expression in breast cancer from the TMA data. The $\mathrm{R}$ and $\mathrm{P}$ values were from Pearson Correlation. (C) Assay of luciferase activities when co-transfected with pMIR-Luc-Jab1 3'UTR, or -mut and let-7d mimics or miRNA control. Data were normalized to control. (D) qRT-PCR analysis of Jab1 expression after let-7d overexpression was shown. (E, F) Western blot results of Jab1 protein level by transfecting with let-7d mimics (E) and let-7d inhibitors (F). $\beta$-Actin was used as an internal control. ${ }^{* *} \mathrm{P}<0.001$.
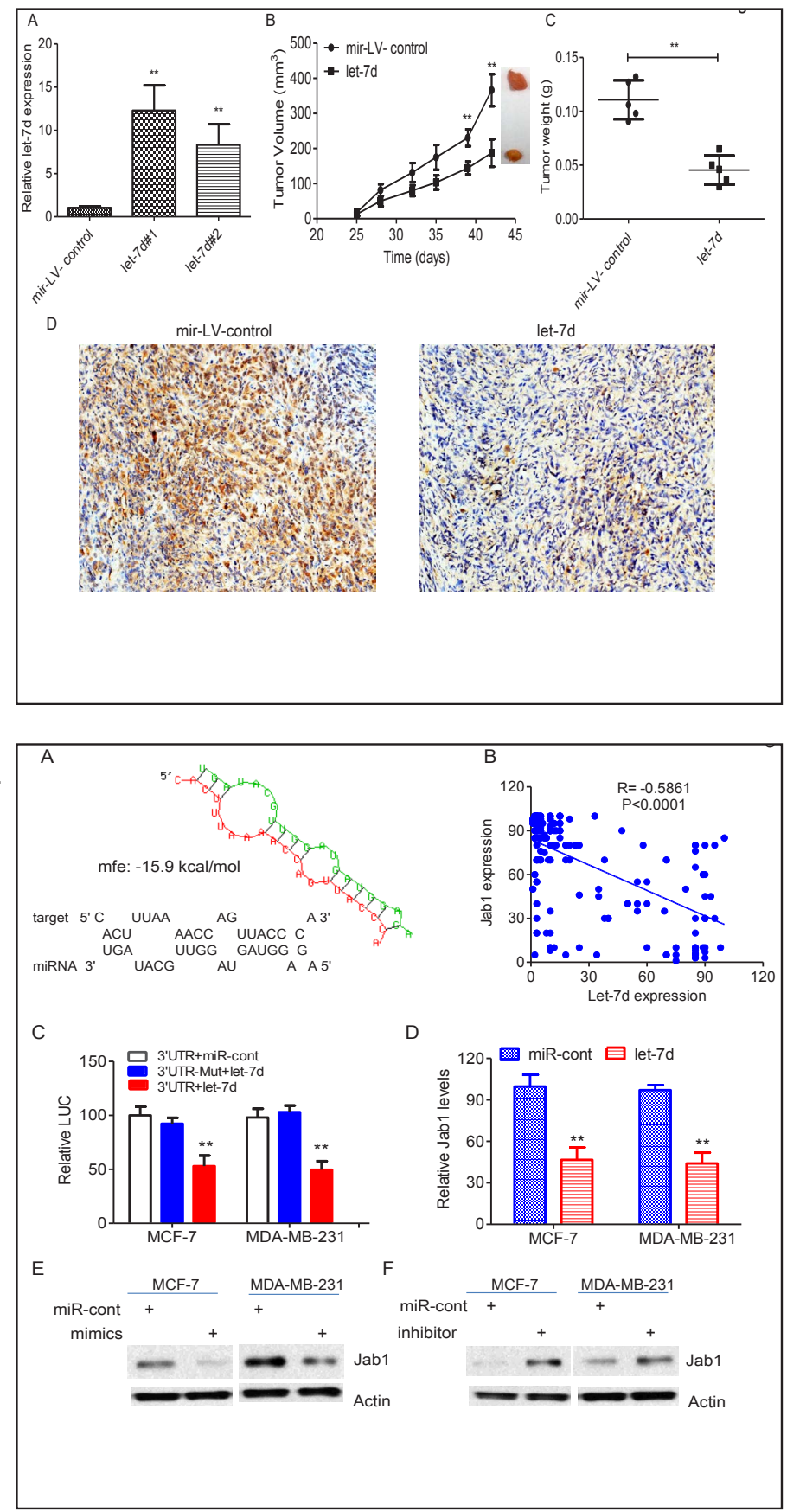
let-7d was associated with Jab1 in breast cancer patients $(\mathrm{R}=$ $-0.5861, \mathrm{P}<0.0001$; Fig. 4B).

Next, to confirm that Jab1 is a target of let-7d, we used miR luciferase constructs containing the 3'UTR of Jab1, pMIR-lucJab1 3'UTR. Treatment of cotransfected MCF-7 and MDAMB-231 cells with let-7d mimics significantly decreased luciferase activity in cells with pMIR-lucJab1 3'UTR (Fig. 4C), indicating that 3'UTR is functional binding sites of let-7d. Besides this, the sequences within the pMIR-lucJab1 3'UTR binding sites were mutated, leading to loss of let$7 \mathrm{~d}$-mediated suppression of luciferase activity (Fig. 4C).

Accordingly, the expression of Jab1 was reduced dramatically at both mRNA and protein levels after let-7d mimics treatment (Fig. 4D and 4E). In contrast, miR-24 inhibition increased Jab1 expression (Fig. 3F). These results suggest that let$7 d$ directly targets Jab1 mRNA, resulting in Jab1 repression.

\section{Correlation of let-7d/Jab1 expression with clinical outcome}

The mean survival time of patients with high let-7d tumors (131 months) were significantly longer than that of patients with low let-7d tumors (117 months). However, the mean survival time of patients with high Jab1 expression (118 months) was significantly shorter than that of patients with low expression (128 months).

Survival analysis using the Kaplan-Meier method showed that low expression of let-7d tended to correlate with poor OS ( $\mathrm{P}=0.046$; Fig. $5 \mathrm{~A})$ and poor MFS $(\mathrm{P}=0.117$; Fig. 5B). However, increased Jab1 expression was significantly associated with worse OS ( $\mathrm{P}=0.031$; Fig. $5 \mathrm{C})$ and MFS $(\mathrm{P}=0.001$; Fig. 5D). We also analysed the survival in different subtypes of breast cancer and observed similar results (see online suppl. material, Suppl. Fig. 1 and 2).

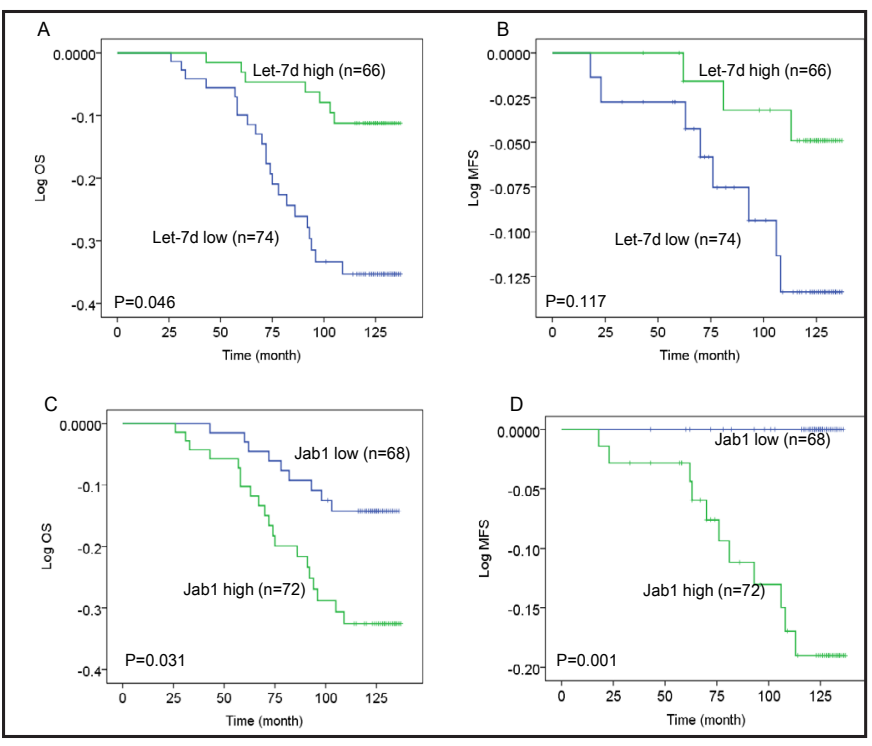

Fig. 5. Let-7d and Jab1 predict survival in breast cancer. KaplanMeier analyses of the association between let-7d (A and B) or Jab1 (C and D) expression and overall survival (OS) or metastasisfree survival (MFS).
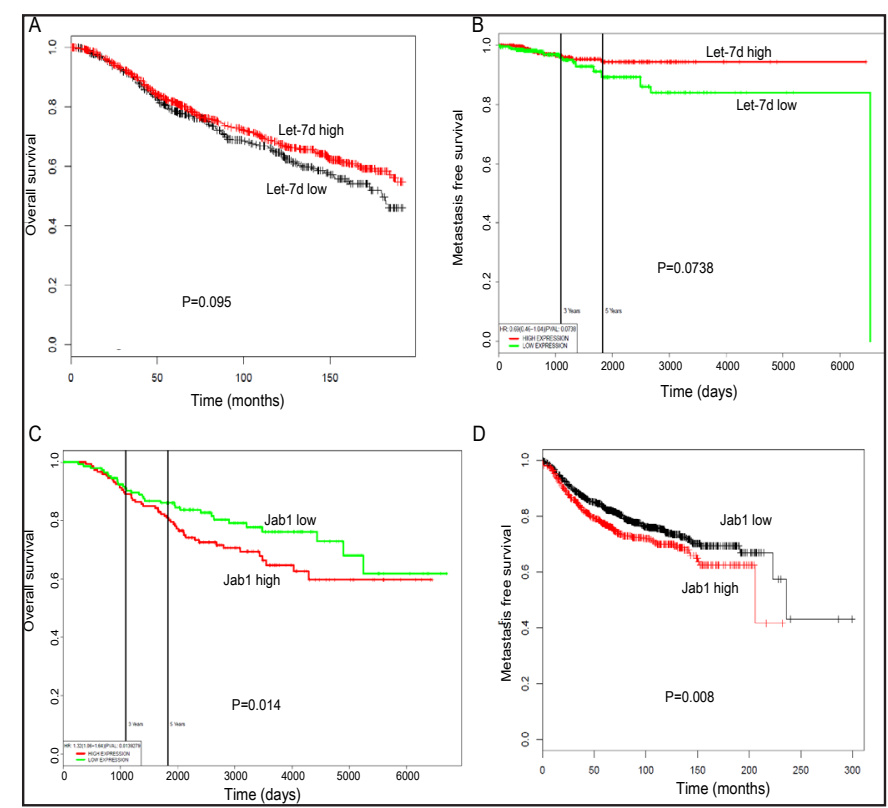

Fig. 6. Correlation of the expression of let-7 or Jab1 with the survival of patients with breast cancers. In vivo mRNA data from Kaplan-Meier Plotter database (http://kmplot.com/analysis/) and PROGgeneV2-PROGNOSTICS database (http://watson. compbio.iupui.edu/chirayu/proggene/database/) were used to assess the association between let-7d (A and B) or Jab1 ( C and D) expression and overall survival or metastasis-free survival. 
We also examined the association between let-7d or Jab1 and survival of breast cancer patients in two online databases: Kaplan-Meier Plotter database and PROGgeneV2PROGNOSTICS. The online data showed that low levels of let-7d or high levels of Jab1 were correlated with worse survival in breast cancer (Fig 6) was in line with our findings from the clinical specimens.

\section{Discussion}

Let-7d is a family member of let-7 which functions as a tumor suppressor in various human cancers. Direct targets of let-7 include oncogenes such as RAS and HMGA2 [23, 32]. In the present study, we found expression of let-7d was lower in breast cancer tissue than in normal breast tissue. These findings indicate that let-7d may be tightly associated with breast cancer progression.

A variety of investigations suggested that miRNA involved in cancer progression, and thus overexpression or suppression of miRNAs would be promising therapeutic strategies for the treatment of cancer. Ning Y, et al., found that let-7 d was downregulated in ovarian cancer tissues compared with normal ovarian tissues [22]. Let-7d was also reported to be downregulated in oral squamous cell carcinoma [33] and renal cell carcinoma [24], which was consistent with our results in breast cancer. However, in some cases of head and neck squamous cell carcinoma (HNSCC), let-7d was significantly upregulated in tumor tissue [34]. These findings illustrated that let-7 d level may depend on tissue types, and plays a different biological role in different cancers. We found that overexpression of let-7d significantly suppressed tumor growth both in vitro and in vivo, indicating let-7d may be a potential target for breast cancer patients.

miRNAs regulate cell proliferation, invasion, and metastasis in various human cancers. Functional studies have indicated that ectopic expression of let-7d significantly inhibits cell proliferation, migration, as well as tumor growth, metastasis in renal cell carcinoma [24]. In line with these results, here we demonstrate that let-7d overexpression remarkably inhibits cell proliferation, meanwhile, decreases invasion in breast cancer cells. Bioinformatics analysis suggested that Jab1 may be a potential target gene of let-7d. Stepwise studies revealed that let-7d directly bound to the 3'-UTR of Jab1, and decreased Jab1 expression. Besides this, overexpression of let-7d evidently reduces Jab1 expression in mice tumor tissues. These results highlight the potential role of let-7d in breast cancer.

Jab1 is aberrantly expressed in a number of cancer types and contributes to the cancer progression [8]. Elevated deposition of Jab1 has been particularly associated with cell proliferation, cell cycle, and therapy response and correlated with worse cancer prognosis [8]. It has also been reported that Jab1 is elevated in breast cancer tissues compared with normal tissues $[7,10]$. In the current study, we reproduced similar conclusion as previous studies that high expression of the Jab1 level was associated with worse OS and MFS in breast cancer.

In conclusion, low let-7 d expression and high Jab1 expression confer poor prognosis of breast cancer. Overexpression of let-7d results in growth suppression in vitro and in vivo and decreases invasion ability, which is at least in part achieved by targeting Jab1. On the basis of these results, let-7d and Jab1 may be potential biomarkers for breast cancer patients.

\section{Acknowledgements}

We thank Dr. Kashif Rafi Zahid at Central China Normal University for helping editing the manuscript. This work was supported in part by the fund from the National Natural Science Foundation of China (81372816; 81673033), the Fundamental Research Funds for the Central Universities (2042018kf0091), Zhongnan Hospital of Wuhan University Science, Technology and Innovation Seed Fund (CXPY2017029), and the Natural Science Foundation of Hubei Province (2018CFB510). 


\section{Cellular Physiology Cell Physiol Biochem 2018;47:2126-2135 \begin{tabular}{ll|l} 
and Biochemistry Published onlıne: July 04, 2018 & $\begin{array}{l}\text { C } 2018 \text { The Author(s). Published by S. Karger AG, Basel } \\
\text { www.karger.com/cpb }\end{array}$ \\
\hline
\end{tabular}}

Wei et al.: Let-7d Targets Jab1 in Breast Cancer

\section{Disclosure Statement}

No conflict of interests exists.

\section{References}

-1 DeSantis CE, Fedewa SA, Goding Sauer A, Kramer JL, Smith RA, Jemal A: Breast cancer statistics, 2015: Convergence of incidence rates between black and white women. CA Cancer J Clin 2016;66:31-42.

-2 Telli ML, Timms KM, Reid J, Hennessy B, Mills GB, Jensen KC, Szallasi Z, Barry WT, Winer EP, Tung NM, Isakoff SJ, Ryan PD, Greene-Colozzi A, Gutin A, Sangale Z, Iliev D, Neff C, Abkevich V, Jones JT, Lanchbury JS, Hartman AR, Garber JE, Ford JM, Silver DP, Richardson AL: Homologous Recombination Deficiency (HRD) Score Predicts Response to Platinum-Containing Neoadjuvant Chemotherapy in Patients with TripleNegative Breast Cancer. Clin Cancer Res 2016;22:3764-3773.

-3 Benevolenskaya EV, Islam AB, Ahsan H, Kibriya MG, Jasmine F, Wolff B, Al-Alem U, Wiley E, Kajdacsy-Balla A, Macias V, Rauscher GH: DNA methylation and hormone receptor status in breast cancer. Clin Epigenetics 2016;8:17.

4 Benzina S, Beauregard AP, Guerrette R, Jean S, Faye MD, Laflamme M, Maicas E, Crapoulet N, Ouellette RJ, Robichaud GA: Pax-5 is a potent regulator of E-cadherin and breast cancer malignant processes. Oncotarget 2017;8:12052-12066.

5 Pusztai L, Mazouni C, Anderson K, Wu Y, Symmans WF: Molecular classification of breast cancer: limitations and potential. Oncologist 2006;11:868-877.

6 Zhou F, Pan Y, Wei Y, Zhang R, Bai G, Shen Q, Meng S, Le XF, Andreeff M, Claret FX: Jab1/Csn5-Thioredoxin Signaling in Relapsed Acute Monocytic Leukemia under Oxidative Stress. Clin Cancer Res 2017;23:44504461.

-7 Lu R, Hu X, Zhou J, Sun J, Zhu AZ, Xu X, Zheng H, Gao X, Wang X, Jin H, Zhu P, Guo L: COPS5 amplification and overexpression confers tamoxifen-resistance in ERalpha-positive breast cancer by degradation of NCoR. Nat Commun 2016;7:12044.

8 Pan Y, Yang H, Claret FX: Emerging roles of Jab1/CSN5 in DNA damage response, DNA repair, and cancer. Cancer Biol Ther 2014;15:256-262.

-9 Liu G, Claret FX, Zhou F, Pan Y: Jab1/COPS5 as a Novel Biomarker for Diagnosis, Prognosis, Therapy Prediction and Therapeutic Tools for Human Cancer. Front Pharmacol 2018;9:135.

10 Esteva FJ, Sahin AA, Rassidakis GZ, Yuan LX, Smith TL, Yang Y, Gilcrease MZ, Cristofanilli M, Nahta R, Pusztai L, Claret FX: Jun activation domain binding protein 1 expression is associated with low p27(Kip1)levels in node-negative breast cancer. Clin Cancer Res 2003;9:5652-5659.

11 Wightman B, Ha I, Ruvkun G: Posttranscriptional regulation of the heterochronic gene lin-14 by lin-4 mediates temporal pattern formation in C. elegans. Cell 1993;75:855-862.

12 Gunaratne PH, Creighton CJ, Watson M, Tennakoon JB: Large-scale integration of MicroRNA and gene expression data for identification of enriched microRNA-mRNA associations in biological systems. Methods Mol Biol 2010;667:297-315.

13 Baek D, Villen J, Shin C, Camargo FD, Gygi SP, Bartel DP: The impact of microRNAs on protein output. Nature 2008;455:64-71.

14 Chivukula RR, Shi G, Acharya A, Mills EW, Zeitels LR, Anandam JL, Abdelnaby AA, Balch GC, Mansour JC, Yopp AC, Maitra A, Mendell JT: An essential mesenchymal function for miR-143/145 in intestinal epithelial regeneration. Cell 2014;157:1104-1116.

15 Adhami M, Haghdoost AA, Sadeghi B, Malekpour Afshar R: Candidate miRNAs in human breast cancer biomarkers: a systematic review. Breast Cancer 2017;10.1007/s12282-017-0814-8

16 Bussing I, Slack FJ, Grosshans H: let-7 microRNAs in development, stem cells and cancer. Trends Mol Med 2008;14:400-409.

17 Thomson JM, Parker J, Perou CM, Hammond SM: A custom microarray platform for analysis of microRNA gene expression. Nat Methods 2004;1:47-53.

18 Shimizu S, Takehara T, Hikita H, Kodama T, Miyagi T, Hosui A, Tatsumi T, Ishida H, Noda T, Nagano H, Doki Y, Mori M, Hayashi N: The let-7 family of microRNAs inhibits Bcl-xL expression and potentiates sorafenibinduced apoptosis in human hepatocellular carcinoma. J Hepatol 2010;52:698-704. 


\section{Cellular Physiology Cell Physiol Biochem 2018;47:2126-2135 \begin{tabular}{l|l} 
DOI: 10.1159/000491523 & $\begin{array}{l}\text { O 2018 The Author(s). Published by S. Karger AG, Basel } \\
\text { www.karger.com/cpb }\end{array}$ \\
\hline
\end{tabular} \\ Wei et al.: Let-7d Targets Jab1 in Breast Cancer}

19 Zhao B, Han H, Chen J, Zhang Z, Li S, Fang F, Zheng Q, Ma Y, Zhang J, Wu N, Yang Y: MicroRNA let-7c inhibits migration and invasion of human non-small cell lung cancer by targeting ITGB3 and MAP4K3. Cancer Lett 2014;342:43-51.

20 Liu K, Zhang C, Li T, Ding Y, Tu T, Zhou F, Qi W, Chen H, Sun X: Let-7a inhibits growth and migration of breast cancer cells by targeting HMGA1. Int J Oncol 2015;46:2526-2534.

-21 Shell S, Park SM, Radjabi AR, Schickel R, Kistner EO, Jewell DA, Feig C, Lengyel E, Peter ME: Let-7 expression defines two differentiation stages of cancer. Proc Natl Acad Sci U S A 2007;104:11400-11405.

22 Ning YX, Luo X, Xu M, Feng X, Wang J: Let-7d increases ovarian cancer cell sensitivity to a genistein analog by targeting c-Myc. Oncotarget 2017;8:74836-74845.

23 Di Fiore R, Drago-Ferrante R, Pentimalli F, Di Marzo D, Forte IM, Carlisi D, De Blasio A, Tesoriere G, Giordano A, Vento R: Let-7d miRNA Shows Both Antioncogenic and Oncogenic Functions in Osteosarcoma-Derived 3AB-OS Cancer Stem Cells. J Cell Physiol 2016;231:1832-1841.

24 Su B, Zhao W, Shi B, Zhang Z, Yu X, Xie F, Guo Z, Zhang X, Liu J, Shen Q, Wang J, Li X, Zhang Z, Zhou L: Let-7d suppresses growth, metastasis, and tumor macrophage infiltration in renal cell carcinoma by targeting COL3A1 and CCL7. Mol Cancer 2014;13:206.

-25 Ramberg H, Alshbib A, Berge V, Svindland A, Tasken KA: Regulation of PBX3 expression by androgen and Let-7d in prostate cancer. Mol Cancer 2011;10:50.

-26 Pan Y, Wang S, Su B, Zhou F, Zhang R, Xu T, Zhang R, Leventaki V, Drakos E, Liu W, Claret FX: Stat3 contributes to cancer progression by regulating Jab1/Csn5 expression. Oncogene 2017;36:1069-1079.

27 Pan Y, Zhang Q, Atsaves V, Yang H, Claret FX: Suppression of Jab1/CSN5 induces radio- and chemosensitivity in nasopharyngeal carcinoma through changes to the DNA damage and repair pathways. Oncogene 2013;32:2756-2766.

-28 Wang S, Pan Y, Zhang R, Xu T, Wu W, Zhang R, Wang C, Huang H, Calin CA, Yang H, Claret FX: Hsa-miR-24-3p increases nasopharyngeal carcinoma radiosensitivity by targeting both the 3'UTR and 5'UTR of Jab1/CSN5. Oncogene 2016;35:6096-6108.

-29 Lanczky A, Nagy A, Bottai G, Munkacsy G, Szabo A, Santarpia L, Gyorffy B: miRpower: a web-tool to validate survival-associated miRNAs utilizing expression data from 2178 breast cancer patients. Breast Cancer Res Treat 2016;160:439-446.

30 Goswami CP, Nakshatri H: PROGgeneV2: enhancements on the existing database. BMC Cancer 2014;14:970.

31 Pan Y, Zhang Q, Tian L, Wang X, Fan X, Zhang H, Claret FX, Yang H: Jab1/CSN5 negatively regulates p27 and plays a role in the pathogenesis of nasopharyngeal carcinoma. Cancer Res 2012;72:1890-1900.

-32 Lamperska KM, Kolenda T, Teresiak A, Kowalik A, Kruszyna-Mochalska M, Jackowiak W, Blizniak R, Przybyla W, Kapalczynska M, Kozlowski P: Different levels of let-7d expression modulate response of FaDu cells to irradiation and chemotherapeutics. PLoS One 2017;12:e0180265.

-33 Manikandan M, Deva Magendhra Rao AK, Arunkumar G, Manickavasagam M, Rajkumar KS, Rajaraman R, Munirajan AK: Oral squamous cell carcinoma: microRNA expression profiling and integrative analyses for elucidation of tumourigenesis mechanism. Mol Cancer 2016;15:28.

-34 Lamperska KM, Kozlowski P, Kolenda T, Teresiak A, Blizniak R, Przybyla W, Masternak MM, Golusinski P, Golusinski W: Unpredictable changes of selected miRNA in expression profile of HNSCC. Cancer Biomark 2016;16:55-64. 